\title{
A Predictive Model for Inflation in Nigeria
}

\section{Nse S. Udoh ${ }^{1}$ and Anietie S. Isaiah ${ }^{2}$}

The study estimates a dynamic model using quarterly data spanning 1995 to 2016. Four dynamic models: level lagged variables, differenced lagged variables, log-transformed lagged variables and differenced log-transformed lagged variables were considered. The best predictive model was selected based on the Schwarz Information Criterion (SIC) value. From the empirical results, the level form models performed better than the differenced form models. On the basis of model parsimony, the level lagged model was the preferred model among the set of selected models. Predictions obtained from the model indicate that the model is stable as actual interest rate (IR) values, fall well within the computed $95 \%$ prediction interval. The study concludes that previous values of $I R$ and money supply (MS) are significant in predicting future inflation rates in Nigeria.

Keywords: Autoregressive Distributed Lag Model, Inflation Rate, Predictive Model.

JEL Classification: E52.

DOI: $10.33429 /$ Cjas.09218.5/6

\subsection{Introduction}

Inflation is defined as a sustained increase in the overall price level over time. During periods of high inflation, the value of the domestic currency diminishes which negatively affects the economy (Folorunso and Abiola, 2000). Nigeria is witnessing high inflation with economic and social implications. As real income falls, due to the eroded purchasing power of the currency, there is a reduction in the amount of goods and services each unit of the currency can buy. Confronted with an already diminished disposable income, consumers are now faced with higher prices owing to higher production costs. The high inflation trend in the country has also led to increased demand by workers, especially those in the public sector, for higher wages. Furthermore, the desire to save and invest has been on the decline, adversely affecting economic growth.

\footnotetext{
${ }^{1}$ Corresponding author: Department of Mathematics and Statistics, University of Uyo, Nigeria; nsesudoh@uniuyo.edu.ng.

${ }^{2}$ Department of Mathematics and Statistics, University of Uyo, Nigeria
} 
Similar to the mandate of most central banks, price stability has remained one of the core mandates of the Central Bank of Nigeria (CBN). The interest in price stability emanates not only from the need to maintain overall macroeconomic balance, but also from the fact that price stability promotes investment, output and employment. However, despite several government policies and programmes in Nigeria, the economy has consistently experienced high inflation with attendant consequences on the most vulnerable.

Since the work by Phillips (1958), most studies on inflation in developed economies have linked inflation with unemployment. Recent studies in these economies have tended to augment the classical Philips approach of inflation modelling with lagged and lead inflation terms (as surrogates for inflation inertia and expectation respectively); measure supply shocks such as relative food price, energy cost and import price and the real unit cost of labour and output gap. This resulted in the expectation-augmented Phillips curve, the New-Keynesian Phillips curve and the expectation mark-up models of inflation modelling (Richards and Stevens, 1987; Franz and Gordon, 1993; Brouwer and Ericsson, 1995).

Extensive studies on inflation using the Philips Curve approach and its variants have been carried out in Nigeria (Adebowale, 2015; and Orji et al., 2015). However, the Philips inflation modelling methodology has been criticized as inadequate in accounting for the dynamic structure of the inflationary process. Particularly, this approach fails to incorporate as many predictor variables as possible, and most times yields a single model from which judgement is based. Perhaps in an attempt to obtain a more robust view of the dynamics of inflation in Nigeria, some authors have used the univariate time series and the error correction and cointegration approaches, employing money growth, income and exchange rate movements as the focal variables. Examples of the use of the univariate time series models include works by Doguwa and Alade (2013), Otu et al. (2014) and Etuk (2017). The error correction and cointegration modelling approach include studies by Folorunso and Abiola (2000); Odusanya and Atanda (2010); Maku and Adelewokan (2013). This paper adds to the literature on inflation in Nigeria by varying the period covered, 
methodology used, variables used and frequency of data among other factors to study the dynamics of inflation in Nigeria. Specifically, this study estimates a dynamic regression using quarterly data of inflation rate (IR), broad money supply (MS), real effective exchange rate (ER) and real gross domestic product (RP) from 1995 to 2016. The advantage of this modelling approach is its ability to deliver results based on underlying economic theory, data characteristics, and practical situations. The main objective of this study is to fit alternative dynamic regression models, select the best-fit model based on some model selection criteria and predict future inflation rates from the selected model.

The rest of the paper is organized as follows. Section two presents the inflationary trend in Nigeria. Theoretical inflation modelling frameworks and selected empirical studies on inflation in Nigeria are discussed in section three. Section four describes the methodology of the study. Preliminary analyses and estimation results are presented in section five, and section six concludes the paper.

\subsection{Some Stylized Facts on Inflation Movement in Nigeria}

The inflationary trend in Nigeria can broadly be categorized into four periods of our national life. The first of these periods is the oil boom era of the 1970s which was characterized by fiscal dominance and considerable macroeconomic imbalances occasioned by the sudden rise in government revenue obtained from crude oil exports. These earnings were invested in gigantic capital projects embarked upon by the government under the Third National Development Plan (1975-1980), see Suleiman (1998) and Masha (2001). Consequently, the period witnessed a sharp increase in money supply with the economy having to contend with serious liquidity challenges. With increased money in circulation and a fragile productive base, the classic case of too much money chasing too few goods ensued. This inevitably led to increase in prices of goods and services. The doubling of the minimum wage in 1975 as recommended by the Udoji Committee further fuelled the rise in the overall level of prices in the economy as the increased income and consequent increased aggregate demand was not matched by increased output. In an attempt to curb the high inflationary trend in the economy which averaged $33.7 \%$ in 1975 , the government liberalized imports which resulted to the huge inflow of goods and in- 
termediate inputs into the country. In addition, banks were encouraged to extend more credit to the productive sectors of the economy in a bid to increase output and create jobs. These government policies helped to push down the inflation rate to $11.8 \%$ in 1979 .

The second period was in the 1980s which was dominated by continued overvaluation of the naira even in the face of dwindling oil revenue leading to significant distortion in the macroeconomic environment in an economy that was import dependent and with balance of payment challenges. Thus, by 1984, the inflation rate had risen to $41.2 \%$ due to devaluation of the naira and expansion in money supply. Responding to the high inflation rate, the government embarked on price control measures, which saw inflation rates falling to $5.5 \%$ in 1985 and $5.4 \%$ in 1986. Again, signs of rising inflation were observed in 1988 and 1989 due to fiscal expansion which was financed by credit from the CBN (Adenekan and Nwanna, 2004). Increased agricultural output helped to reduce the rate of inflation to $8.2 \%$ in 1990 .

Due to high monetary growth and fiscal expansion in the 1990s, Nigeria was confronted with severe inflationary pressures. The inflation rate reached its peak of about $79.9 \%$ in 1995 (Bawa and Abdullahi, 2012). In an effort to reduce the surging inflation rate, the government implemented measures to ensure effective monetary policy, fiscal prudence and stabilization of the exchange rate. These measures resulted in a reduction in the inflation rate from its peak in 1995 to $6.6 \%$ in 1999.

Nigeria witnessed a sharp increase in inflation from $6.9 \%$ in 2000 to about $17.8 \%$ in 2005. This was attributed to government budget deficit over the years. The inflation rate declined to $5.4 \%$ in 2007 due to the implementation of sound monetary and fiscal policies. Inflation rate moderated substantially from $11.6 \%$ in 2008 to $9.7 \%$ in 2015 due to increased agricultural output and sound macroeconomic policies (Figure 1 shows the current trend in inflation and some selected macroeconomic indicators in Nigeria between 1995 to 2016). From the forgoing analysis, it is obvious that inflation remains a serious macroeconomic challenge in Nigeria, 
hence the need for continuous empirical analysis of the inflation trend in Nigeria, in order to support sound macroeconomic policy formulation and management.

IR

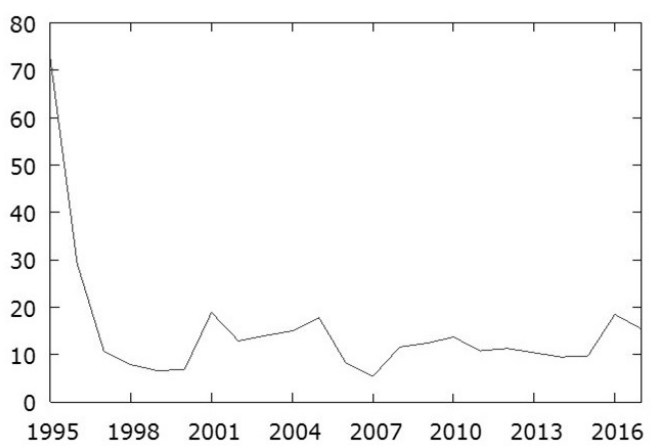

GDP

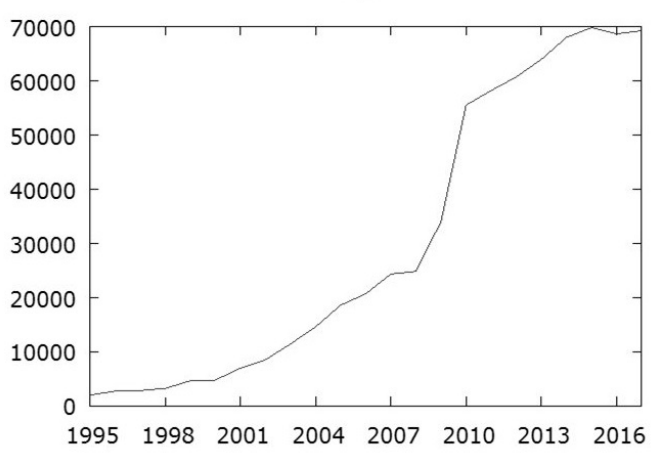

M2

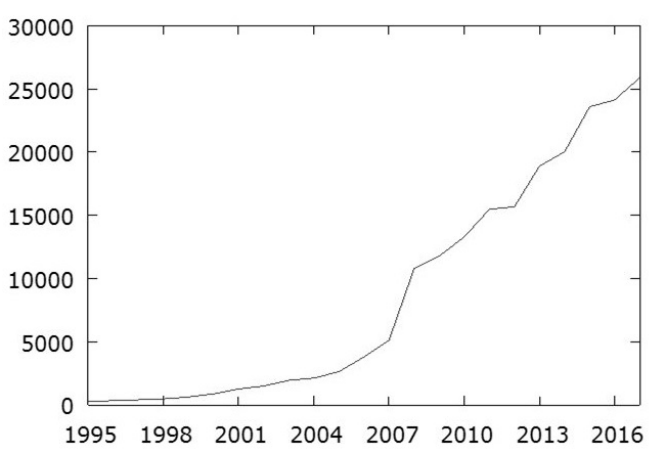

ER

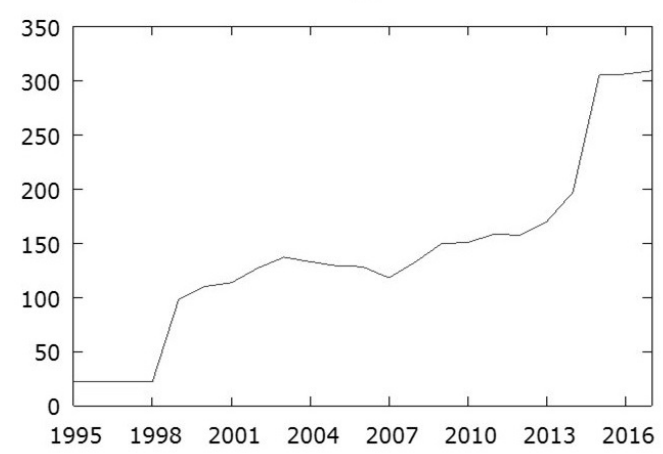

Figure 1: Recent trend in inflation rate (IR), money supply (M2), gross domestic product (GDP) and exchange rate (ER) in Nigeria

\subsection{Review of Literature}

\subsection{Theoretical Framework}

The study of the determinants and economic implications of inflation has given rise to one of the most extensive debates in the literature. The vast discussion on inflation differs in assumptions, due to a range of views about the causes of inflation and also, the disparity between developed and developing countries. This subsection presents outlines of some of the theoretical underpinnings of the determinants of inflation.

\section{The Purchasing Power Parity Theory}

The theory explains the changes in exchange rates in terms of differentials between 
countries. Proponents of this theory are of the view that for countries practicing flexible exchange rate regimes, changes in exchange rate impacts on inflation, especially in small and open developing economies. Exchange rate depreciation directly affects the prices (in domestic currency units) of tradable goods, but may also indirectly affect the general price level if pricing decisions are affected by the cost of imported input (Agenor and Montiel, 1996). However, the evidence of the validity of the theory is mixed for less developed countries; see Mahdavi and Zhou (1994) among others.

\section{The Monetarist Theory}

According to the monetarists, inflation is a domestic monetary phenomenon that arises when the central bank increases the money supply in excess of the demand for money. It is asserted that the money supply is exogenous and under the control of the authorities. The monetarist model of the determinants of inflation is derived from the money demand function and is based on the hypothesis that inflation varies positively with the rate of change of money supply and negatively with the rate of change of real income, ceteris paribus. In practice, financing fiscal deficits through money creation by the central bank may raise prices and erode foreign reserves (Agenor and Montiel, 1996). Monetarists see the short-term solution to inflation as the implementation of a contractionary or restrictive monetary policy.

\section{The Structuralist Theory}

Proponents of the structuralist theory cite the presence of structural bottlenecks, especially in developing countries as key causes of inflation. Essentially, structuralists distinguish between basic or structural inflationary pressures and mechanisms that transmit or propagate such pressures (Kirkpatrick and Nixson, 1987). Major structural bottlenecks identified in structuralist analyses include distorting government policies, the conflict between investors and workers over the distribution of income between profits and wages (Agenor and Montiel, 1996), inelastic food supply, the foreign exchange and government budget constraints. In this view, the bottlenecks lead to price increases, which are transmitted into the inflationary process. Structuralists therefore argue that the factors that the orthodox view 
regards as the causes of inflation should rather be seen as symptoms of the underlying structural rigidities in developing countries.

\section{The Structuralist-Monetarist (Hybrid) Theory}

Fundamental omissions from the monetarist theory of inflation are structural or cost-push elements that cause inflation. The monetarists explain cost increases in terms of changes in the money supply, especially if the monetary authorities adopt an accommodation policy that seeks to prevent real output from falling. Cost-push inflation, which is absent in monetarist models, is a potentially serious problem in small open developing countries, where increases in foreign prices may be an important cause of domestic inflation. In recent years, several authors have developed models with monetarist and structuralist features by directly augmenting the monetarist approach with cost-push factors. Some of the approaches have been to model the fiscal deficit as the original force and the propagating mechanism in the inflationary process to include structuralist considerations into monetarist models (Chibber, 1992; Jha, 1994) and to account for money supply dynamics in structuralist models (Aghevli and Khan, 1978; Agenor and Montiel, 1996). The choice of variables employed in this paper was informed by these theories and past empirical studies.

\subsection{Empirical Review of Literature}

The subject of inflation has continued to engage the attention of researchers in Nigeria. Consequently, several different variables and models have been employed in an attempt to investigate the nature and determinants of inflation in Nigeria.

Olubusoye and Oyaromade (2008) examined the main determinants of inflation in Nigeria employing data from 1970 to 2003 with the aid of error correction mechanism. Evidence from the study showed that expected inflation, petroleum product prices and real exchange rate, exert significant effects on the trend of inflation in Nigeria. Later, Imimole and Enoma (2011) investigated the effect of exchange rate depreciation on Nigeria's inflationary process. The study used data from 1986 to 2008 employing the autoregressive distributed lag model. The study identified inflation inertia, exchange rate depreciation, money supply and real gross domestic 
product as the major determinants of inflation in Nigeria.

Furthermore, Bayo (2011) analyzed the main causes of inflation in Nigeria from 1981 to 2003 using the ordinary least squares approach. The study revealed that fiscal factors, money supply, interest and exchange rates significantly impact on inflation in Nigeria. Olatunji et al. (2012) studied the sources of inflation in Nigeria employing the cointegration and error correction modelling approach. The study showed that exports, imports, food prices, interest and exchange rate were significant in determining the movement of inflation in Nigeria. In recent past, Bawa et al. (2016) analyzed Nigeria's inflationary trend from 1981 to 2015 using the bounds testing (approach to cointegration analysis). Results from the study indicated that inflation inertia, rainfall and money supply significantly influence the inflationary process in Nigeria. Also, several forecasting approaches of inflation exist. Kuhe and Egemba (2010) examined the inflation process in Nigeria using the autoregressive integrated moving average modelling technique. They found ARIMA $(3,1,0)$ to be the best fit for Nigerian inflation. The out-of-sample forecast reveals the continuous rise in inflation throughout the period considered. Chinonso and Justice (2016) applied Box-Jenkins ARIMA model on monthly urban and rural CPI from January 2001 to December 2015 to provide 29 months ahead inflation forecast for Nigeria. The study selected ARIMA $(0,1,0)$ and $\operatorname{ARIMA}(0,1,3)$ as the most optimal model for forecasting Nigeria's inflation.

John and Patrick (2016) Modelled monthly inflation rate for Nigeria using data from January 2000 to June 2015. The study identified ARIMA $(0,1,0)$ x $(0,11)$ for Nigeria's inflationary process because the in-sample forecast obtained was very close to the original series. Inam (2017) analyzed Nigeria's inflation using VAR model. The study used data on inflation rate, money supply, fiscal deficit, real exchange rate, interest rate, changes in import prices and real output over the period 1990 to 2012. The result showed that immediate lag value of inflation largely drives current and future inflation in Nigeria.

Although it is straightforward to forecast with univariate models used by Kuhe and Egemba (2010) among others due to their simple structure, the forecasts, 
however, have no economic insight since they are plain extrapolations from the systematic part of the series being modelled. Also, because univariate models are usually based on a single time series, results from such studies may not be suited for policy analysis as they fail to highlight other important variables which may influence the rate of inflation, especially in an evolving economy like Nigeria. The error correction and cointegration models adopted by Folorunso and Abiola(2000) and others, although useful in examining the inter-relationship between inflation and its presumed determinants from theories, has however been criticized on the premise that test-statistic for these models do not have exact sample distributions since these models require large data sets. Hence, conclusions drawn from such studies should be accepted with caution, particularly, in a developing country like Nigeria with considerable data challenges on some vital economic indices. In an attempt to address the concerns highlighted above, this paper re-examined the determinants of inflation in Nigeria employing the dynamic regression methodology.

\subsection{Methodology}

A central feature of most economic variables is a pronounced time dependence, and it follows that the dependence of a variable, say, $Y_{t}$ on another variable, say, $X_{t}$, is rarely instantaneous and cannot be completed in one time period. Frequently, $Y_{t}$ responds to $X_{t}$ with a time lag. This often necessitates the inclusion of lags of $X_{t}$ in a model relating $Y_{t}$ and $X_{t}$, as additional explanatory variables. That is,

$$
Y_{t}=m+b_{0} X_{t}+b_{t} X_{t-1}+\ldots+b_{q} X_{t-q}+\varepsilon_{t} ; \varepsilon_{t} \approx i i d N\left(0, \sigma^{2}\right)
$$

The model defined in equation (1) is called the distributed lag model. The lagged explanatory variables account for the time adjustment process. Also, the time dependence in economic variables implies that successive values of a variable tend to be fairly close together. This means that we can model the systematic variation in the dependent variable of equation (1) as a function of its own past. This forms the basis of autoregressive modelling. Mathematically, this sort of functional relationship takes the form:

$$
Y=m+a_{1} Y_{t-1}+a_{2} Y_{t-2}+\ldots+a_{p} Y_{t-p}+\varepsilon_{t} ; \varepsilon_{t} \approx i i d N\left(0, \sigma^{2}\right)
$$


Combining the models in equations (1) and (2), we obtain:

$$
\begin{gathered}
Y_{t}=m+a_{1} Y_{t-1}+a_{2} Y_{t-2}+\ldots+a_{p} Y_{t-p}+b_{0} X_{t}+b_{1} X_{t-1}+\ldots+b_{q} X_{t-q}+\varepsilon_{t} \\
=m+\sum_{i=1}^{p} a_{i} Y_{t-i}+\sum_{j=0}^{q} b_{j} X_{t-j}+\varepsilon_{t}
\end{gathered}
$$

where $\varepsilon_{t} \approx \operatorname{iidN}\left(0, \sigma^{2}\right)$ is a white noise error process and $\left|\sum_{i=1}^{p} a_{i}\right|<1$ for dynamic stability, which is analogous to the stationarity condition for autoregressive models. Equation (3) is variously referred to as the general dynamic regression model, time series regression model and the autoregressive distributed lag model. It models the systematic variation in $Y_{t}$ in terms of its own past history, current and past values of $X_{t}$ and a random error component. When several covariate series are considered, equation (3) can be generalized in a straightforward manner as:

$$
Y_{t}=m+\sum_{i=1}^{p} a_{i} Y_{t-i}+\sum_{j=1}^{n} \sum_{k=0}^{q} b_{j k} X_{j, t-k}+\varepsilon_{t}
$$

The processes generating $X_{j, t}$ are assumed to be weakly exogenous for the parameter(s) of interest such that $E\left(e_{t}, X_{j, t}\right)=0$ for all $t$ and $j$. However in the context of this study, the presence of $X_{j, t}$ (that is current values of the explanatory variables) in equation (4) renders it inoperative for prediction, since in the period in which $Y_{t}$ is to be predicted, the current observations on $X_{j, t}$ may not be available yet. In such situations, it is more convenient to replace $X_{j, t}$ with the most recent past values. This is in line with the general time series methodology, where the interest is to quantify how the past evolves into the present and the future. Therefore, we can recast the model in equation (4) as follows:

$$
Y_{t}=m+\sum_{i=1}^{p} a_{i} Y_{t-i}+\sum_{j=1}^{n} \sum_{k=1}^{q} b_{j k} X_{j, t-k}+\varepsilon_{t}
$$

It is easy to see that prediction becomes an option when the model is formulated in this form.

\subsection{Model Specification}

In fitting models to data, four types of the model in equation (5) were specified in line with the estimation methods described in Subsection 2.1 in an attempt to select the best-fit model. These were models with level lagged variables, differenced 
lagged variables, log-transformed lagged variables and differenced log-transformed lagged variables. The specified models are as follows:

Level lagged variables model

$$
I R_{t}=a_{0}+\sum_{j=1}^{13} a_{j} I R_{t-j}+\sum_{j=1}^{13} b_{j} M S_{t-j}+\sum_{j=1}^{13} c_{j} E R_{t-j}+\sum_{j=1}^{13} d_{j} R P_{t-j}+u_{t}
$$

Differenced lagged variables model

$$
\nabla I R_{t}=a_{0}+\sum_{j=1}^{13} a_{j} \nabla I R_{t-j}+\sum_{j=1}^{13} b_{j} \nabla M S_{t-j}+\sum_{j=1}^{13} c_{j} \nabla E R_{t-j}+\sum_{j=1}^{13} d_{j} \nabla R P_{t-j}+u_{t}
$$

Log-transformed lagged variables model

$$
I n I R_{t}=a_{0}+\sum_{j=1}^{13} a_{j} \operatorname{InIR} R_{t-j}+\sum_{j=1}^{13} b_{j} \operatorname{InM} S_{t-j}+\sum_{j=1}^{13} c_{j} \operatorname{InER_{t-j}}+\sum_{j=1}^{13} d_{j} \operatorname{InRP_{t-j}}+u_{t}
$$

Differenced log-transformed lagged variables model

$$
\nabla \ln I R_{t}=a_{0}+\sum_{j=1}^{12} \nabla \ln I R_{t-j}+\sum_{j=1}^{12} \nabla \ln M S_{t-j}+\sum_{j=1}^{12} \nabla \ln E R_{t-j}+\sum_{j=1}^{12} \nabla \ln R P_{t-j}+u_{t}
$$

where $u_{t} \approx i i d N\left(0, \sigma^{2}\right),\left|\sum_{j=1}^{13} a_{j}\right|<1$ for the models defined in equations (6) and (8) to be dynamically stable. IR, MS, ER, RP, N and In are inflation rate, broad money supply, real effective exchange rate, real gross domestic product, first difference operator and natural logarithm, respectively.

\subsection{Test for Stationarity}

For the models defined in equations (7) and (9), we assume that the variables are stationary at first difference. We may need to check whether or not this assumption is valid. This can be achieved by testing for unit roots in the variables. This work employs the Augmented Dickey-Fuller (ADF) test by Dickey and Fuller (1981) to test for unit roots.

The ADF test statistic does not follow the standard student's t-distribution but follows a distribution tabulated by Fuller (1996). Mackinnon (1996) has provided 
an augmented version of the test which is applicable for any number of observations.

\subsection{Variable Selection Methods}

In the models defined in equations (6), (7), (8) and (9) we have assumed that the set of predictor variables included in the models are all fixed. In fitting these models to data, it may turn out that not all the predictor variables are necessary and we may need to systematically weed out the unnecessary ones to arrive at a good parsimonious model. In attempting to obtain a good parsimonious predictive model, efforts will be made to include as many relevant regressors and exclude as many irrelevant ones as possible in the considered model. Hence, two opposing methods of variables selection are employed in this study, namely, the backward elimination and the forward selection methods using Gretl 1.9.91 software. The backward elimination procedure has the advantage of inspecting possible subset models from which the choice of the final model can be made. In addition, it preserve individual and joint contribution of variables to model fit since it starts with all the candidate variables. The forward selection method is faster than the backward elimination method in terms of computational time and yields a single final model. A major drawback of the backward elimination method is that of multicollinearity. Though the forward selection routine checks multicollinearity in models, it fails to account for individual and joint contributions of variables to model fit and the single final model yielded by the procedure may not be optimal in any specified sense (Draper and Smith, 1966).

\subsection{Model Selection Criteria}

Several criteria are used for model comparison and selection in the literature. This paper employs the Schwarz Information Criteria (SIC) in conjunction with the principle of parsimony. The SIC balances the trade-off between model-fit and model complexity and is defined as:

$$
S I C=\ln \left(\frac{R S S}{n}\right)+\frac{K \ln (n)}{n}
$$

where $R S S$ is the residual sum of squares, $\mathrm{n}$ is the sample size, $\mathrm{K}$ is the number of estimated parameters in the model and In is natural logarithm. However, 
it is observed that objective model comparison and selection using SIC can only be achieved if the regressand in the models to be compared are similarly defined (Nielsen, 2007). Hence, each class of fitted models obtained using the backward and forward selection methods will be subjected to pairwise comparison. The model with the lower SIC value will be entertained as the best for the given class of models. From among the selected models, the one with the least number of parameters will be selected as the final predictive model.

\subsection{Residual Analysis}

We have assumed that the error terms in equations (6), (7), (8) and (9), are normal or Gaussian white noise processes. These assumptions can be checked by examining the residuals obtained from fitting the models to data. In the context of this work, we are concerned with violations of the white noise assumption since in such a case the OLS estimates are no longer efficient and the t-test and the F-tests are not reliable. The correlogram and partial correlogram of the residuals and squared residuals of the final selected model will be inspected to guard against possible violations of the white noise assumption and consequent spurious regression charge (Lutkephol and Kratzig, 2004). If the residuals reasonably approximate white noise, $95 \%$ of the correlations will deviate by a factor $\pm 1.96 / \sqrt{T}$ along the zero line of the plots. Where $T$ is the size of the sample.

\subsection{Data}

The study uses quarterly data of inflation rate and real gross domestic product from the National Bureau of Statistics. Quarterly data on broad money supply and monthly data on real effective exchange rate were obtained from the various editions of the Annual Report and Statistical Bulletin of the Central Bank of Nigeria. To be consistent with the other variables, we took quarterly averages of the monthly data on real effective exchange rate. The data covers the period from 1995 to 2016. 


\subsection{Analysis and Results}

\subsection{Time Series Plots of Variables}

The time series plots of the untransformed and the log-transformed variables are presented in Figures 2 and 3 in Appendix I. Figure 2 reveals a general upward trend with some hints of higher variations associated with higher levels of the variables, especially for $M S, E R$ and $R P$. The trend indicates that the variables are nonstationary at levels, while the localized variations suggest that the variables may not be completely linear over time suggesting suitable transformation in order to achieve linearity so that the simple linear model can continue to suffice. Figure 3 shows that the non-uniform variation attributable to higher levels of the variables may have been somewhat reduced by taking the logarithms of the original observations.

\subsection{Unit Root Tests}

The Augmented Dickey-Fuller framework discussed in Subsection 4.3 was used to test the hypothesis of unit roots in the variables. Tests results, assuming 11 lags and variables in their original forms are presented in Tables 1 and 2. The results of the test with intercept but no trend and with intercept and trend both at levels and first differences for each variable are presented in the tables. Results presented in Table 1 indicate that $I R$ is stationary at level with a non-zero mean with constant variance and without a deterministic trend, while $M S, E R$ and $R P$ are not stationary. In order to quantify the evidence of nonstationarity in the variables, the same tests were applied to the first differences of the variables.

Table 1: Results of Augmented Dickey-Fuller Unit Root Test at Levels

\begin{tabular}{|c|c|c|c|c|c|c|c|c|c|}
\hline \multirow[b]{2}{*}{ Series: } & \multicolumn{5}{|c|}{ With intercept } & \multicolumn{4}{|c|}{ With intercept and trend } \\
\hline & & IR & MS & ER & $\mathrm{RP}$ & IR & MS & ER & $\mathrm{RP}$ \\
\hline ADF test Statistics: & & -6.040 & 1.260 & -1.490 & 5.750 & -5.710 & -1.890 & 0.880 & 1.470 \\
\hline \multirow[t]{3}{*}{ Test critical values: } & $1 \%$ & -3.510 & -3.510 & -3.510 & -3.510 & -4.070 & -4.070 & -4.070 & -4.080 \\
\hline & $5 \%$ & -2.900 & -2.900 & -2.900 & -2.900 & -3.460 & -3.460 & -3.460 & -3.470 \\
\hline & $10 \%$ & -2.590 & -2.590 & -2.590 & -2.590 & -3.160 & -3.150 & -3.150 & 3.160 \\
\hline Prob* & & 0.000 & 1.000 & 0.530 & 1.000 & 0.000 & 0.650 & 0.950 & 1.000 \\
\hline
\end{tabular}

Table 2 shows that $I R, M S$ and $E R$ are stationary with a non-zero mean at first 
difference while $R P$ is stationary when trend is accounted for.

Table 2: Results of Augmented Dickey-Fuller Unit Root Test at First Difference

\begin{tabular}{|c|c|c|c|c|c|c|c|c|c|}
\hline \multirow[b]{2}{*}{ Series: } & & \multirow[b]{2}{*}{ IR } & \multicolumn{3}{|c|}{ With intercept } & \multicolumn{4}{|c|}{ With intercept and trend } \\
\hline & & & MS & ER & RP & IR & MS & ER & RP \\
\hline ADF test Statistics: & & -5.460 & -9.500 & -7.790 & -0.310 & -5.590 & -9.820 & -8.170 & -6.960 \\
\hline \multirow[t]{3}{*}{ Test critical values: } & $1 \%$ & -3.510 & -3.510 & -3.510 & -3.510 & -4.070 & -4.070 & -4.070 & -4.080 \\
\hline & $5 \%$ & -2.900 & -2.900 & -2.900 & -2.900 & -3.460 & -3.460 & -3.460 & -3.470 \\
\hline & $10 \%$ & -2.590 & -2.590 & -2.590 & -2.590 & -3.160 & -3.150 & -3.150 & 3.160 \\
\hline Prob* & & 0.000 & 0.000 & 0.000 & 0.920 & 0.000 & 0.000 & 0.000 & 0.000 \\
\hline
\end{tabular}

\subsection{Estimation Results}

The models defined in equations (6), (7), (8) and (9) respectively were fitted to data using the backward elimination method. After several sequential reduction steps, the reduced models in Tables $3,4,5$, and 6 were obtained.

Table 3: Estimation Results for the Model in equation (6) via the Backward Elimination Method

\begin{tabular}{|c|c|c|c|c|c|}
\hline \multicolumn{6}{|c|}{ Dependent variable: IR } \\
\hline & Coeff & Std. Error & t-ratio & p-value & \\
\hline const & 6.331 & 2.358 & 2.685 & 0.009 & $* * *$ \\
\hline ER_4 & 0.083 & 0.038 & 2.190 & 0.032 & $* *$ \\
\hline ER 5 & -0.163 & 0.042 & -3.850 & 0.000 & $* * *$ \\
\hline ER 8 & 0.066 & 0.023 & 2.899 & 0.005 & $* * *$ \\
\hline $\mathbf{R P}_{-} 1$ & 0.049 & 0.024 & 2.015 & 0.048 & $* *$ \\
\hline RP_ 5 & -0.059 & 0.029 & -2.021 & 0.048 & $* *$ \\
\hline RP 8 & -0.270 & 0.101 & -2.679 & 0.009 & $* * *$ \\
\hline RP 12 & 0.281 & 0.112 & 2.512 & 0.015 & $* *$ \\
\hline IR 1 & 0.845 & 0.067 & 12.541 & 0.000 & $* * *$ \\
\hline IR_ 4 & -0.560 & 0.101 & -5.566 & 0.000 & $* * *$ \\
\hline IR_ 5 & 0.440 & 0.109 & 4.031 & 0.000 & $* * *$ \\
\hline IR 12 & 0.265 & 0.084 & 3.166 & 0.002 & $* * *$ \\
\hline IR 13 & -0.263 & 0.075 & -3.531 & 0.001 & $* * *$ \\
\hline R-sq & 0.791 & & Adj R-sq & 0.750 & \\
\hline$F(12,61)$ & 19.248 & & P-value(F) & 0.000 & \\
\hline SIC & 385.298 & & AIC & 355.345 & \\
\hline Rho & 0.188 & & Durbin's h & 1.981 & \\
\hline
\end{tabular}


Table 4: Estimation Results for the Model in Equation (7) via the Backward Elimination Method

\begin{tabular}{|c|c|c|c|c|c|}
\hline \multicolumn{6}{|c|}{ Dependent variable: IR } \\
\hline & Coeff & Std. Error & t-ratio & $\mathrm{p}$-value & \\
\hline$\overline{\text { const }}$ & -0.053 & 0.358 & -0.148 & 0.883 & \\
\hline d_MS_3 & 0.152 & 0.072 & 2.108 & 0.039 & $* *$ \\
\hline d_ER_4 & 0.077 & 0.038 & 2.050 & 0.044 & $* *$ \\
\hline d_IR_4 & -0.485 & 0.099 & -4.906 & 0.000 & $* * *$ \\
\hline d_IR_12 & 0.225 & 0.082 & 2.738 & 0.008 & $* * *$ \\
\hline $\bar{R}$-sq & 0.348 & & Adj R-sq & 0.309 & \\
\hline$F(4,68)$ & 9.055 & & P-value(F) & 0.000 & \\
\hline SIC & 374.517 & & AIC & 363.064 & \\
\hline rho & 0.202 & & $\mathrm{D}-\mathrm{W}$ & 1.573 & \\
\hline
\end{tabular}

Table 5: Estimation Results for the Model in Equation (8)

via the Backward Elimination Method

\begin{tabular}{lccccc}
\hline Dependent variable: IR & & & & \\
& Coeff & Std. Error & t-ratio & p-value & \\
\hline const & 4.729 & 1.843 & 2.566 & 0.014 & $* *$ \\
1_MS_1 & -1.755 & 0.395 & -4.438 & 0.000 & $* * *$ \\
1_MS_3 & -1.239 & 0.448 & -2.764 & 0.008 & $* * *$ \\
1_MS_4 & 1.709 & 0.403 & 4.242 & 0.000 & $* * *$ \\
1_MS_10 & 2.043 & 0.422 & 4.845 & 0.000 & $* * *$ \\
1_MS_11 & -1.415 & 0.390 & -3.629 & 0.001 & $* * *$ \\
1_ER_2 & 0.415 & 0.166 & 2.500 & 0.016 & $* *$ \\
1_ER_3 & -0.851 & 0.154 & -5.530 & 0.000 & $* * *$ \\
1_ER_6 & -1.284 & 0.170 & -7.557 & 0.000 & $* * *$ \\
1_ER_8 & 1.427 & 0.172 & 8.305 & 0.000 & $* * *$ \\
1_ER_14 & 0.408 & 0.175 & 2.330 & 0.024 & $* *$ \\
1_RP_1 & 1.707 & 0.396 & 4.316 & 0.000 & $* * *$ \\
1_RP_3 & 3.402 & 0.813 & 4.182 & 0.000 & $* * *$ \\
1_RP_4 & -3.675 & 0.560 & -6.564 & 0.000 & $* * *$ \\
1_RP_7 & -3.580 & 0.873 & -4.099 & 0.000 & $* * *$ \\
1_RP_12 & 3.663 & 0.628 & 5.838 & 0.000 & $* * *$ \\
1_RP_13 & -1.432 & 0.492 & -2.911 & 0.005 & $* * *$ \\
1_IR_1 & 0.729 & 0.061 & 11.952 & 0.000 & $* * *$ \\
1_IR_3 & -0.387 & 0.084 & -4.583 & 0.000 & $* * *$ \\
1_IR_4 & -0.290 & 0.099 & -2.932 & 0.005 & $* * *$ \\
1_IR_5 & 0.516 & 0.096 & 5.360 & 0.000 & $* * *$ \\
1_IR_6 & -0.371 & 0.096 & -3.878 & 0.000 & $* * *$ \\
1_IR_7 & -0.293 & 0.090 & -3.274 & 0.002 & $* * *$ \\
1_IR_8 & 0.226 & 0.074 & 3.071 & 0.004 & $* * *$ \\
1_IR_11 & -0.266 & 0.071 & -3.757 & 0.000 & $* * *$ \\
1_IR_12 & 0.255 & 0.070 & 3.629 & 0.001 & $* * *$ \\
1_IR_14 & -0.268 & 0.050 & -5.323 & 0.000 & $* * *$ \\
\hline R-sq & 0.939 & & Adjd R-sq & 0.905 & \\
F(26,47) & 27.755 & & P-value(F) & 0.000 & \\
SIC & 39.954 & & AIC & -22.256 & \\
rho & -0.050 & & Durbin's h & -0.510 & \\
\hline ******and * represents & $1 \% ; 5 \%$ and & $10 \%$ significance levels, \\
respectively & & & & & \\
& & & & &
\end{tabular}


Table 6: Estimation Results for the Model in Equation (9)

via the Backward Elimination Method

\begin{tabular}{|c|c|c|c|c|c|}
\hline \multicolumn{6}{|c|}{ Dependent variable: $\nabla \ln I R$} \\
\hline & Coeff & Std. Error & t-ratio & p-value & \\
\hline const & -0.205 & 0.045 & -4.536 & 0.000 & $* * *$ \\
\hline ld_MS_4 & 1.417 & 0.415 & 3.418 & 0.001 & $* * *$ \\
\hline Id_MS_10 & 1.455 & 0.427 & 3.409 & 0.001 & $* * *$ \\
\hline ld_MS_13 & 1.053 & 0.421 & 2.500 & 0.015 & $* *$ \\
\hline Id_ER_1 & 0.298 & 0.133 & 2.247 & 0.029 & $* *$ \\
\hline ld_ER_4 & 0.592 & 0.231 & 2.567 & 0.013 & $* *$ \\
\hline 1d_ER_6 & -1.617 & 0.240 & -6.746 & 0.000 & $* * *$ \\
\hline ld_ER_7 & -0.647 & 0.234 & -2.763 & 0.008 & $* * *$ \\
\hline ld_ER_8 & 1.281 & 0.230 & 5.559 & 0.000 & $* * *$ \\
\hline 1d_ER_14 & 0.854 & 0.261 & 3.277 & 0.002 & $* * *$ \\
\hline 1d_RP_2 & 1.652 & 0.401 & 4.117 & 0.000 & $* * *$ \\
\hline 1d_RP_3 & 1.713 & 0.433 & 3.958 & 0.000 & $* * *$ \\
\hline 1d_RP_9 & 1.733 & 0.478 & 3.627 & 0.001 & $* * *$ \\
\hline Id_RP_12 & 1.517 & 0.448 & 3.386 & 0.001 & $* * *$ \\
\hline ld_IR_3 & -0.190 & 0.075 & -2.541 & 0.014 & $* *$ \\
\hline ld_IR_4 & -0.438 & 0.081 & -5.421 & 0.000 & $* * *$ \\
\hline ld_IR_6 & -0.253 & 0.081 & -3.123 & 0.003 & $* * *$ \\
\hline 1d_IR_9 & -0.188 & 0.078 & -2.423 & 0.019 & $* *$ \\
\hline R-sq & 0.741 & & Adj R-sq & 0.661 & \\
\hline$F(17,55)$ & 9.276 & & P-value(F) & 0.000 & \\
\hline SIC & 52.726 & & AIC & 11.498 & \\
\hline rho & 0.099 & & D-W & 1.760 & \\
\hline
\end{tabular}

respectively

Estimation results show that the models fit the data reasonably well. Also, the estimates for level and differenced lagged variables models in Tables 3 and 4 tend to select less complex regression equations as against the log-transformed models as shown in Tables 5 and 6 . The complexity of the log-transformed models may be due to the fact that it has helped improve linearity in the variables, thereby promoting the significance of many lags. However, as noted earlier in Subsection 4.5, objective comparisons across the models in Tables 3-6 based on their SIC statistics cannot be made because the dependent variable in the models are of different forms.

Refitting the models defined in equations (6), (7), (8) and (9) using the forward selection algorithm gives the results shown in Tables 7, 8, 9, and 10 . 
Table 7: Estimation Results for the Model in Equation (6) via the Forward Selection Method

\begin{tabular}{|c|c|c|c|c|c|}
\hline \multicolumn{6}{|c|}{ Dependent variable: IR } \\
\hline & Coeff & Std. Error & t-ratio & p-value & \\
\hline Const & 1.572 & 0.688 & 2.284 & 0.025 & $* *$ \\
\hline MS_2 & 0.041 & 0.018 & 0.008 & 0.008 & $* *$ \\
\hline IR_1 & 0.796 & 0.071 & 10.623 & 0.000 & $* * *$ \\
\hline IR_4 & 0.382 & 0.113 & 3.665 & 0.000 & $* * *$ \\
\hline IR 5 & -0.218 & 0.114 & -2.120 & 0.038 & $* *$ \\
\hline R-sq & 0.681 & & Adj R-sq & 0.663 & \\
\hline $\mathrm{F}(4,76)$ & 12522.575 & & P-value(F) & 0.000 & \\
\hline SIC & 292.546 & & AIC & 281.233 & \\
\hline Rho & 0.244 & & Durbin's h & 2.403 & \\
\hline
\end{tabular}

Table 8: Estimation Results for the Model in Equation (7) via the Forward Selection Method

\begin{tabular}{lccccc}
\multicolumn{5}{c}{ Dependent variable: d_IR } \\
& Coeff & Std. Error & t-ratio & p-value & \\
\hline const & 0.200 & 0.342 & 0.584 & 0.561 & \\
d_ER_6 & -0.091 & 0.039 & -2.364 & 0.021 & $* *$ \\
d_IR_4 & -0.473 & 0.102 & -4.620 & 0.000 & $* * *$ \\
d_IR_8 & 0.267 & 0.115 & 2.419 & 0.016 & $* *$ \\
d_IR_12 & 0.206 & 0.085 & 2.425 & $0.018 \quad * *$ \\
\hline R-sq & 0.278 & & Adj R-sq & 0.258 & \\
F(4,76) & 13.49 & & P-value(F) & 0.000 & \\
SIC & 373.3 & & AIC & 366.441 & \\
Rho & 0.182 & & D-W & 1.618 & \\
***;** and * represents 1\%.5\% and 10\% significance
\end{tabular}

***; ** and * represents $1 \% ; 5 \%$ and $10 \%$ significance levels, respectively 
Table 9: Estimation Results for the Model in Equation (8) via the Forward Selection Method

\begin{tabular}{|c|c|c|c|c|c|}
\hline \multicolumn{6}{|c|}{ Dependent variable: 1_IR } \\
\hline \multicolumn{6}{|c|}{ Coeff Std. Error } \\
\hline const & 4.3443 & 2.1262 & 2.0433 & 0.0458 & $\div \div$ \\
\hline 1_MS_1 & -1.8052 & 0.4221 & -4.2769 & 0.0001 & $\% * *$ \\
\hline 1_MS_4 & 1.3320 & 0.3967 & 3.3575 & 0.0014 & $* * *$ \\
\hline 1_MS_10 & 1.4529 & 0.4552 & 3.1918 & 0.0023 & $* * *$ \\
\hline 1_MS_11 & -1.3227 & 0.4371 & -3.0264 & 0.0038 & $* * *$ \\
\hline 1_ER_3 & -0.3894 & 0.1478 & -2.6357 & 0.0109 & $* *$ \\
\hline 1_ER_6 & -1.3708 & 0.1959 & -6.9989 & 0.0000 & $* * *$ \\
\hline 1_ER_8 & 1.6945 & 0.1848 & 9.1697 & 0.0000 & $* * *$ \\
\hline 1_RP_1 & 1.4072 & 0.4618 & 3.0470 & 0.0036 & $* * *$ \\
\hline 1_RP_3 & 2.0095 & 0.6246 & 3.2171 & 0.0022 & $* * *$ \\
\hline 1_RP_4 & -3.0651 & 0.8280 & -3.7017 & 0.0005 & $* * *$ \\
\hline 1_RP_7 & -1.8762 & 0.7055 & -2.6595 & 0.0102 & $* *$ \\
\hline 1_RP_8 & 2.6342 & 0.8523 & 3.0908 & 0.0031 & $* * *$ \\
\hline 1_RP_9 & -1.2805 & 0.5745 & -2.2291 & 0.0299 & $* *$ \\
\hline 1_IR_1 & 0.6379 & 0.0611 & 10.4420 & 0.0000 & $* * *$ \\
\hline 1_IR_4 & -0.3400 & 0.0802 & -4.2391 & 0.0001 & $* * *$ \\
\hline 1_IR_5 & 0.2928 & 0.1028 & 2.8491 & 0.0062 & $* * *$ \\
\hline 1_IR_6 & -0.1895 & 0.0811 & -2.3366 & 0.0231 & $* *$ \\
\hline 1_IR_14 & -0.1420 & 0.0457 & -3.1061 & 0.0030 & $* * *$ \\
\hline R-sq & 0.888 & & Adj R-sq & 0.852 & \\
\hline $\begin{array}{l}\Gamma(10, \\
=E 1\end{array}$ & 24.265 & & P-value(F) & 0.000 & \\
\hline $\mathrm{SIC}$ & 50.200 & & $\mathrm{AIC}$ & 6.423 & \\
\hline rho & -0.074 & & Durbin's h & -0.751 & \\
\hline
\end{tabular}


Table 10: Estimation Results for the Model in Equation (10)

via the Forward Selection Method

\begin{tabular}{|c|c|c|c|c|c|}
\hline \\
\hline \multicolumn{6}{|c|}{$\begin{array}{l}\text { Dependent variable: } \nabla \operatorname{lnIR} \\
\qquad \text { Coeff } \quad \text { Std }\end{array}$} \\
\hline const & -0.063 & 0.040 & -1.572 & 0.121 & \\
\hline ld_MS_4 & 1.693 & 0.486 & 3.485 & 0.001 & $* * *$ \\
\hline 1d_MS_10 & 1.081 & 0.468 & 2.310 & 0.024 & $* *$ \\
\hline 1d_ER_6 & -1.258 & 0.262 & -4.800 & 0.000 & $* * *$ \\
\hline 1d_ER_8 & 0.874 & 0.264 & 3.305 & 0.002 & $* * *$ \\
\hline 1d_RP_3 & -2.225 & 0.603 & -3.688 & 0.000 & $* * *$ \\
\hline 1d_RP_11 & 2.197 & 0.705 & 3.118 & 0.003 & $* * *$ \\
\hline Id_IR_3 & -0.269 & 0.087 & -3.093 & 0.003 & $* * *$ \\
\hline Id_IR_4 & -0.344 & 0.088 & -3.905 & 0.000 & $* * *$ \\
\hline ld_IR_7 & -0.223 & 0.083 & -2.681 & 0.009 & $* * *$ \\
\hline R-sq & 0.600 & & Adj R-sq & 0.540 & \\
\hline $\mathrm{F}(9,60)$ & 10.008 & & P-value(F) & 0.000 & \\
\hline SIC & 52.296 & & AIC & 29.811 & \\
\hline Rho & 0.208 & & D-W & 1.485 & \\
\hline
\end{tabular}

The results show that the forward selection method selects regression equations with much scaled down parameters, especially so for the unlogged models, perhaps due to its ability to mitigate multicollinearity problems in the estimated models. The estimated models generally provide reasonably good fit to the data.

\subsection{Pairwise Comparison between same classes of Models obtained using the Backward Elimination and Forward Selection Methods}

It is observed from equations $10,11,12$, and 13 that the regressand in the different model types considered were not similar, implying that direct comparison across the estimated models based on their SIC values was unrealistic because the regressand in the model types are quite different both in terms of value and physical interpretation as the scale of measurements are not the same. Hence, the relative magnitude of SIC was the criteria used in pairwise comparison between same classes of models yielded by both the backward elimination and forward selection methods. This was because SIC penalize for model complexity than all other known model comparison criteria. Tables 11 and 12 show that the level form model obtained using the forward selection method was superior to the one obtained by the backward selection criteria as indicated by their SIC values. For the level log-transformed model, the model obtained by employing the backward 
elimination procedure appears to be superior. The relatively lower SIC value for the differenced untransformed model yielded by the backward elimination criterion indicates that it is superior to the one selected by the forward selection algorithm, while the forward selection procedure selected a relatively superior model for the differenced log-transformed model. Therefore, on the basis of SIC, the models in Tables $6,7,8$ and 10 appear generally superior, thus were entertained as tentative predictive models, which implies that the models in Tables 3, 4, 5 and 9 were discarded.

Table 11: Comparison criterion of models obtained using the backward elimination method

\begin{tabular}{cc}
\hline $\begin{array}{c}\text { Model type (Represented } \\
\text { by Regressor) }\end{array}$ & SIC \\
\hline IR & 385.30 \\
$\nabla I R$ & 379.52 \\
$\operatorname{lnIR}$ & 39.95 \\
$\ln \nabla \mathrm{IR}$ & 52.73 \\
\hline
\end{tabular}

Table 12: Comparison criteria of models obtained using the forward selection method

\begin{tabular}{cc}
\hline $\begin{array}{c}\text { Model type (Represented } \\
\text { by Regressor) }\end{array}$ & SIC \\
\hline IR & 292.55 \\
$\nabla I R$ & 373.31 \\
$\operatorname{lnIR}$ & 50.20 \\
$\ln \nabla \mathrm{IR}$ & 52.30 \\
\hline
\end{tabular}

\subsection{Final Model Selection using the Principle of Parsimony}

The criterion employed in selecting the final predictive model from the set of tentative predictive models in Tables 6-10 was the relative parsimoniousness of the models taken individually. The use of the principle of parsimony is in accord with estimation procedures employed; where the goal is to obtain a model with reasonably fewer parameters and reasonably good predictive ability as the most acceptable predictive model. Also, the use of this principle was necessitated by the fact that a model with a large number of parameters may be subject to large estimation errors which may impair the reliability of predictions generated from such model. Consequently, on the basis of the principle of parsimony, the model 
with levels lagged variables in Table 7 with 4 parameters appear to be the best, hence was selected as the final predictive model. The model reveals that current IR values depends on previous values of IR at the first, fourth and fifth lags and past MS at the second lag, with the immediate past IR value observed to be the most important variable while MS at lag two is the least important. It was stated in Subsection 4.1 that modeling time series variables using the regression approach could lead to spurious regression results. Figures 4 and 5 in Appendix II, show that our final model is not spurious since all the correlations lie well within the $\pm 1.961 / \sqrt{T}$ bound. That is, residuals from the model are white noise and conclusions on the model are valid. Table 13 summarizes the prediction performance of the model. The objective was to obtain a prediction of $I R_{T+k}$ given the information set up to time $T$. We defined the information set available at time $T$ as past values of $I R, M S, E R$ and $R P$. Hence the predicted $I R$ values are out-of-sample predictions.

Table 13: Eight Quarters Forecast of Inflation

Rates for 2019-2020

\begin{tabular}{cccc}
\hline Period & prediction & std. error & $\begin{array}{c}95 \% \text { Prediction } \\
\text { interval }\end{array}$ \\
\hline $2019 \mathrm{Q} 1$ & 11.9221 & 1.6952 & $(1.1943,17.7252)$ \\
$2019 \mathrm{Q} 2$ & 12.0365 & 2.9972 & $(1.1863,19.6834)$ \\
$2019 \mathrm{Q} 3$ & 12.1503 & 3.1014 & $(1.2848,20.7231)$ \\
$2019 \mathrm{Q} 4$ & 12.2605 & 3.2008 & $(1.9896,23.2120)$ \\
$2020 \mathrm{Q} 1$ & 13.3828 & 3.7408 & $(2.9663,25.4569)$ \\
$2020 \mathrm{Q} 2$ & 13.5056 & 4.0556 & $(3.3002,26.6669)$ \\
$2020 \mathrm{Q} 3$ & 14.6257 & 4.4113 & $(3.7113,29.0002)$ \\
$2020 \mathrm{Q} 4$ & 14.7509 & 4.9989 & $(3.8005,29.8114)$ \\
\hline
\end{tabular}

\subsection{Conclusion and Policy Implications}

Evidence that expected inflation (denoted by lagged $I R$ terms) constitute the most significant predictors of inflation in Nigeria is established in the study. The prominence of expected inflation in impacting on current inflation rate, perhaps, indicates the anticipatory factor in the Nigerian inflationary process. Therefore, efforts should be made by relevant authorities to discourage hoarding and panic buying so as to reduce inflation expectation in the economy. The study also finds evidence that money supply exerts significant influence on the inflationary trend in Nigeria. The explanation for this could be monetary growth and fiscal expan- 
sion. Therefore, measures to ensure effective monetary policy and fiscal discipline should be implemented by the government.

\section{References}

Adenekan, A. T. and Nwanna, G. A. (2004). Inflation Dynamics in a developing economy: An error correction approach. African Review of Money Finance and Banking, 77-99

Adebowale, B. K. (2015). The relationship between inflation and unemployment in Nigeria. Institute of Graduate Studies and Research Eastern Mediterrancan University Gazimagusa, North Cyprus.

Aghevil, B. B. and Khan, M. S. (1978). Government deficits and the inflationary process in developing countries, IMF Staff Papers, Vol. 25, pp. 388-416.

Agnor, P. R. and Montiel, P. J. (1996). Development macroeconomics. Princeton University Press, Princeton, New Jersey.

Bawa, S. and Abdullahi, I. S. (2012). Threshold effect of inflation on economic growth in Nigeria, CBN Journal of Applied Statistics, Vol. 3, No. 1, pp. 43-63.

Bawa. S. and Abdullahi, I. S. and Ibrahim, A. (2016) Analysis of inflation dynamics in Nigeria (1981 - 2015). CBN Journal of Applied Statistics, Vol. 7, No. 1 , pp. $43-63$.

Bayo, F. (2011). Determinants of inflation in Nigeria: An empirical analysis. International Journal of Humanities and Social Sciences, Vol. 1, No. 18, pp. $262-271$

Brouwer de, G. and Ericsson, N. R. (1995). Modelling inflation in Australia. Economic Analysis and Research Department Discussion Paper No. 9510, Reserve Bank of Australia, Sydney

Chibber, A. (1992). Exchange reforms, supply responses, and inflation in Africa. In: Goldin, I. and Winters, L. A. (Eds.), Open economies: Structural adjustment and agriculture, Cambridge University Press, Cambridge

Chinonso, U. E. and Justice, O. I. (2016). Modelling Nigerian's urban and rural inflation using Box-Jenkins model. Scientific Paper Series on Management, Economic Engineer in Agriculture and Rural Development, Vol. 16, No. 4, pp. $61-68$

Cottrel, A. and Lucchetti, R. J. (2014). Grelt User's Guide. Version 1.9.91 (2014-07-28). 
Dickey, D. A. and Fuller, W. A. (1981). Likelihood ratio statistics for autoregressive time series with a unit root. Econometrica, Vol. 49, pp. 1057-1072

Draper, N. R. and Smith, H. (1966). Applied regression analysis. John Wiley and Sons Inc., New York.

Etuk, H. E. (2017). Statistical intervention analysis of Nigerian monthly inflation. CARD International Journal of Management Studies, Business and Entrepreneurship Research Vol. 2, No. 4

Folorunso, B. A. and Abiola, A. G. (2000). The long-run determinants of inflation in Nigeria, 1970-1998. Nigerian Journal of Economic and Social Statistics, Vol. 42, No. 1, pp. 37-53.

Franz, W. and Gordon, R. J. (1993). German and American wage price dynamics: Differences and common themes. European Economic Review, Vol. 37, No. 4, pp. $719-762$.

Fuller, W. A. (1996). Introduction to statistical time series. 2nd ed., John Wiley and Sons, New York

Imimole, B. and Enoma, A. (2011). Exchange rate depreciation and inflation in Nigeria (1986-2008), Business and Economics Journal, Vol. 2011: BEJ-28.

Inam, U. S. (2017). Forecasting Inflation in Nigeria: A vector autoregression approach. International Journal of Economics, Commerce and Mgt. Vol. 5, No. 1, pp. 92-104

Jha, R. (1994). Macroeconomics for developing countries. Routledge, New York

John, E. E. and Patrick, U. U. (2016). Short-term forecasting of Nigerian inflation rates using seasonal ARIMA model. Science Journal of Applied Mathematics and Statistics, Vol. 4, No. 3, pp. 101-107

Kirkpatrick, C. and Nixon, F. (1987). Inflation and stabilization policy in LDCs. In: Gemmel, N. (Ed.), Surveys in Development Economics, Basil Blackwell, Oxford.

Kuhe, D. A. and Egemba, R. C. (2016). Modelling and forecasting CPI inflation in Nigeria: Application of autoregressive integrated moving average homokedastic model. Journal of Scientific and Engineering Research, Vol. 3, No. 2, pp. 57-66

Lutkephol, H. and Kratzig, M. (2004). Applied time series econometrics. Cambridge University Press, Cambridge.

Mackinnon, J. G. (1996). Numerical distribution functions for unit root and cointegration tests. Journal of Applied Econometrics, Vol. 14, pp. 563-577 
Mahdavi, S. and Zhou, S. (1994). Purchasing power parity in high inflation countries: Further evidence. Journal of Macroeconomics, Vol. 16, pp. 403422 .

Maku, A. O. and Adelowokan, O. A. (2013). Dynamics of inflation in Nigeria: An autoregressive approach. European Journal of Humanities and Social Sciences, Vol. 22, pp. 1-7.

Masha, I. (2000). New perspectives on inflation in Nigeria. CBN Economic and Financial Review, Volume 38, No. 2, June.

Nielsen, H. B. (2007). Dynamic models for stationary time series. Lecture Notes, Department of Economics, University of Copenhagen, Denmark

Odusanya, I. A. and Atanda, A. (2010). Analysis of inflation and its determinants in Nigeria. Pakistan Journal of Social Sciences, Vol. 7. Doi: 10.3923/pjssci.2010.97.100. /.

Olatunji, G.B., Omotosho, O. A., Ayinde, O. E. and Ayinde, K. (2010). Determinants of inflation in Nigeria: A cointegration approach, Paper presented at the Joint 3rd African Association of Agricultural Economists (AAAE) Conference, Cape Town, South Africa, September 19-23

Olubusoye, O. E. and Oyaromade, R. (2008). Modelling the inflation process in Nigeria, AERC Research Paper 182. African Economic Research Consortium, Nairobi, Kenya

Otu, O. A., Osuji, G. A., Jude, O., Ifeyinwa, M. H. and Iheagwara, A. I. (2014). Application of SARIMA models in modelling and forecasting Nigeria's inflation rates. American Journal of Applied Mathematics and Statistics, Vol. 2, No. 1 , pp. $16-28$

Orji, A., Anthony-Orji, O. I. and Okafor, J. C. (2015). Asian Economic and Financial Review Vol. 5, No. 5, pp. 766-778.

Phillips, A. W. (1958). The Relation between unemployment and the rate of change of money wage rates in the United Kingdom, 1861-1957. Economica, Vol. 25, No. 100, pp. 283-299.

Richards, T. and Stevens, G. (1987). Estimating the inflationary effects of depreciation. Research Discussion Paper No. 8713, Reserve Bank of Australia, Sydney.

Suleiman, B. S. (1998) Inflationary Effects of the petroleum industry on the Nigerian Economy. Jos Journal of Economics Vol.1 No.1. 


\section{APPENDIX I}

IR

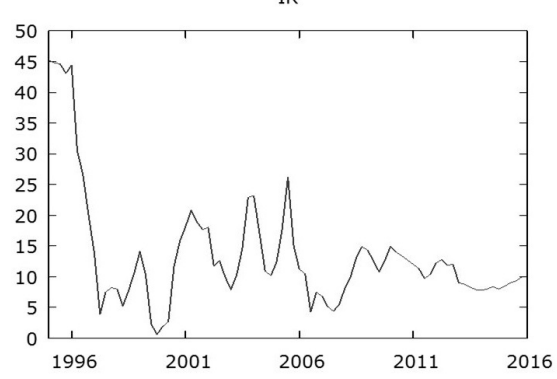

ER

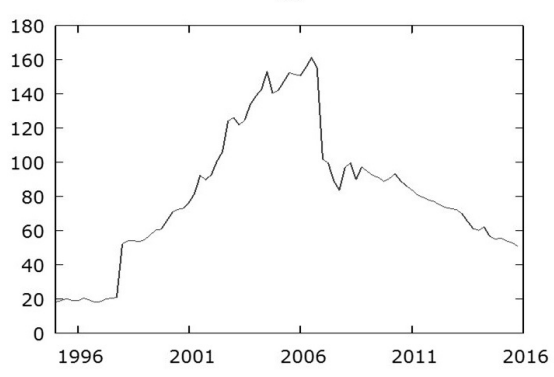

MS

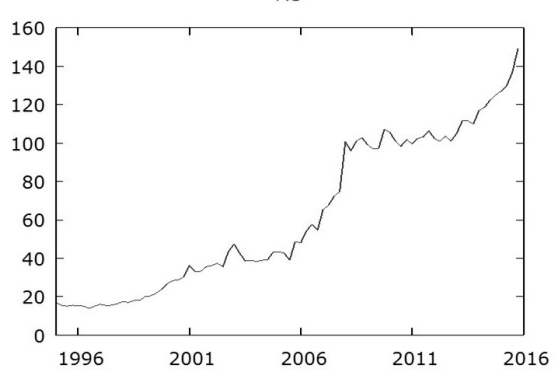

RP

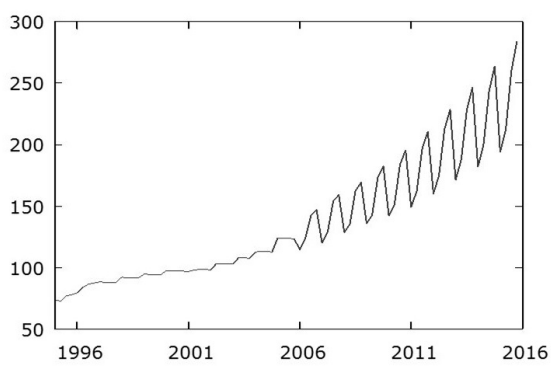

Figure 2: Time series plots of the untransformed IR, MS, ER and RP variables
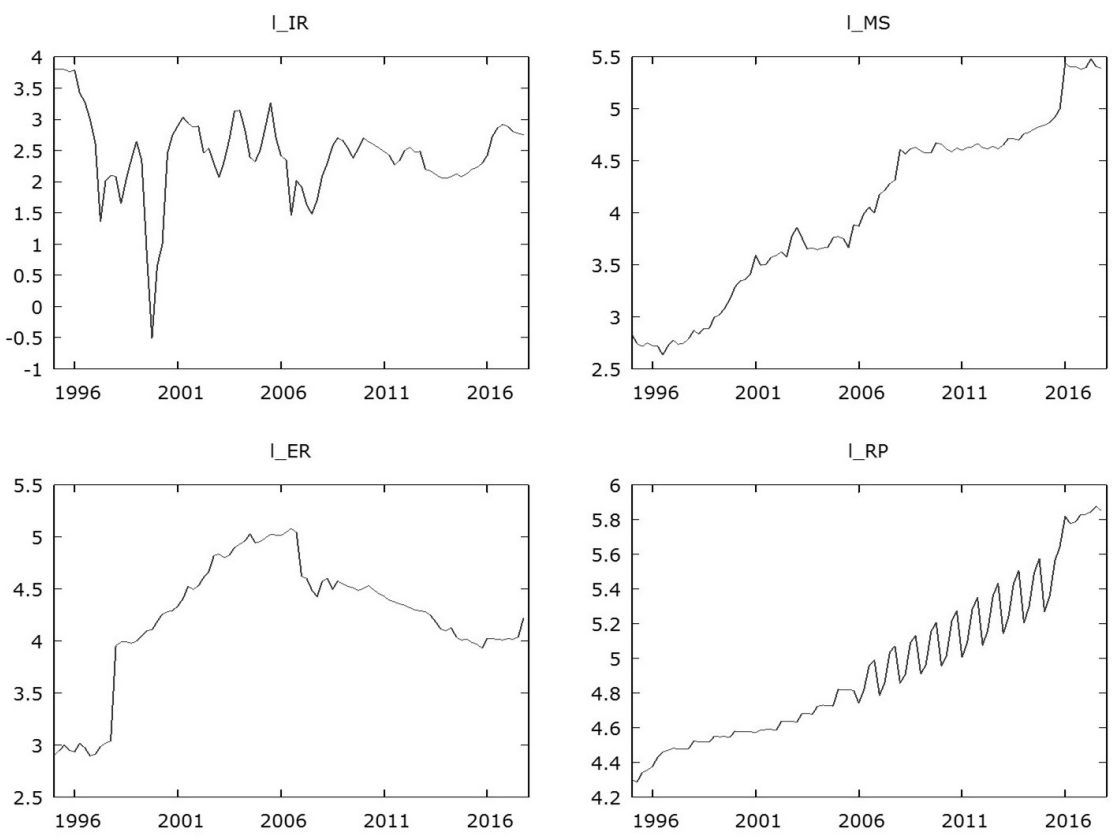

Figure 3: Time series plots of the log-transformed IR, MS, ER and RP variables 


\section{APPENDIX II}
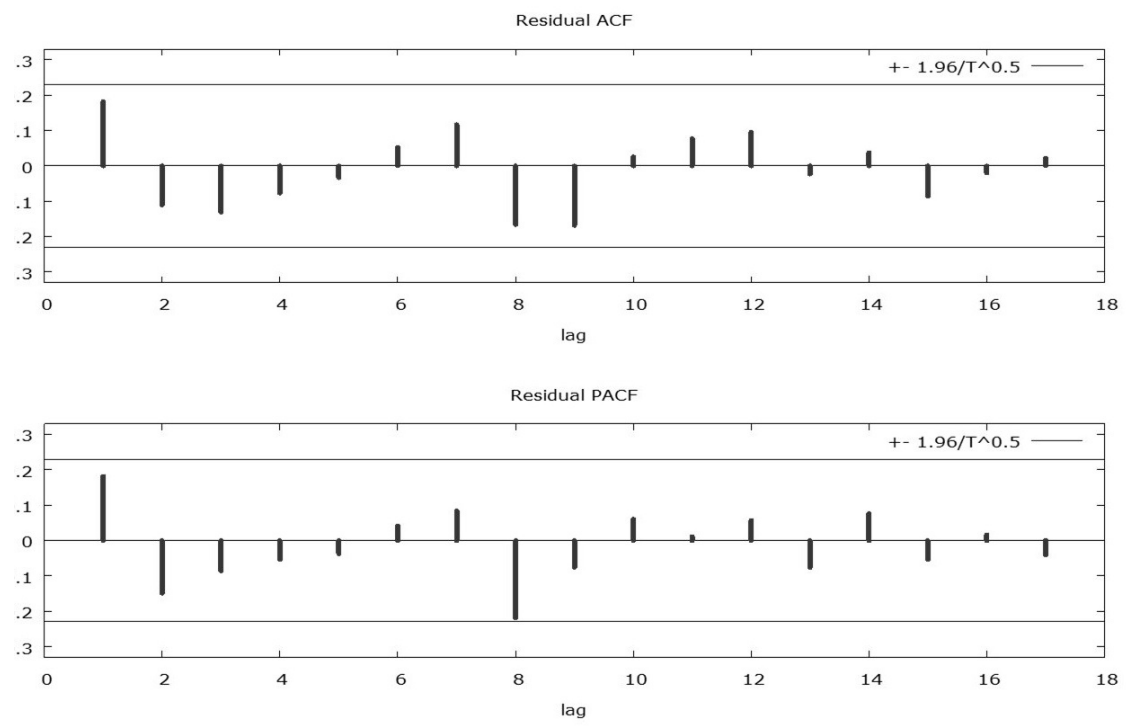

Figure 4: Standardized residual ACF and PACF for the estimated model with differenced lagged variables of Table 7
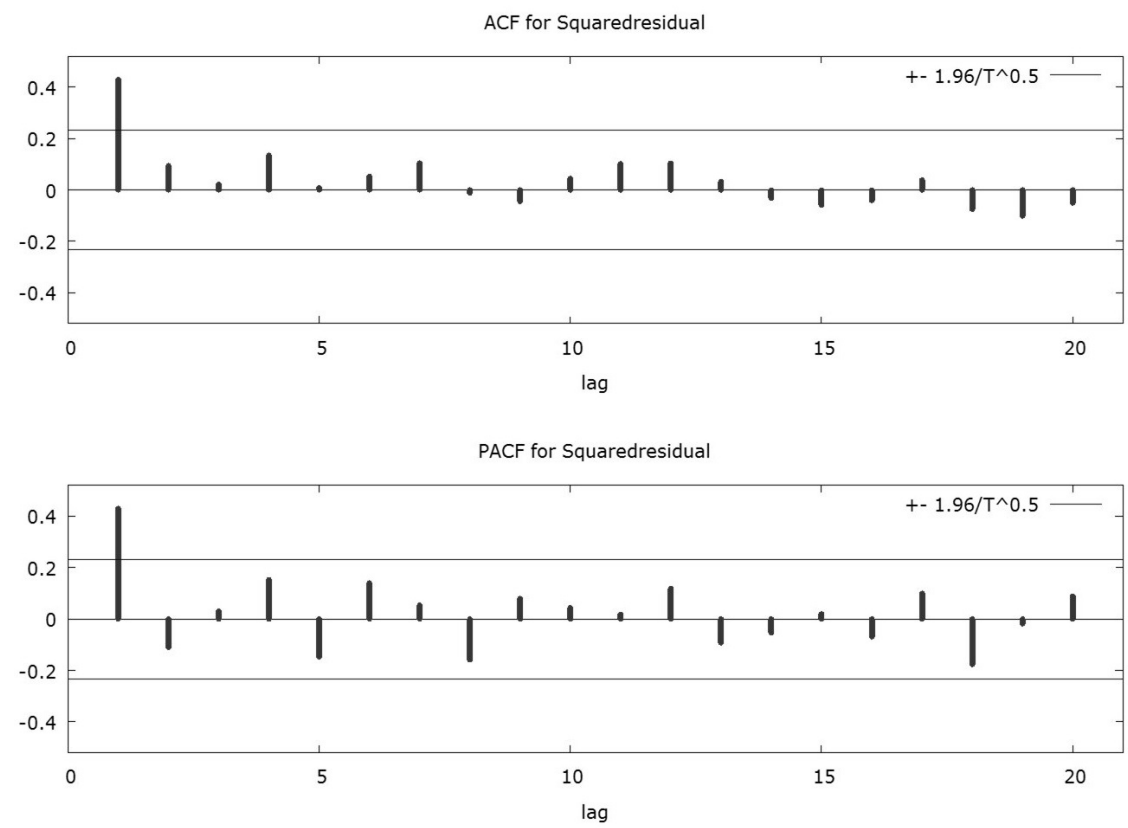

Figure 5: Squared standardized residual ACF and PACF for the estimated model with differenced lagged variables of equation of Table 7 